\title{
2.4 Синтез полупроводниковой пленки с помощью суперионика
}

Наиболее естественный путь получения окислов металлов, в том числе ванадия - окисление металла кислородом газовой фазы. Течение и результат окисления зависят от времени и кислородного потенциала газовой фазы $\boldsymbol{\pi}[182]$, который в простейшем случае смеси кислорода с нейтральным газом, взятой при общем давлении I атм., определяется температурой Т и парциальным давлением кислорода $\mathrm{p}$

$$
\pi=\mathrm{RT} \cdot \ln \mathrm{p}
$$

где R - универсальная газовая постоянная, T - температура, p - давление кислорода.Совокупность сочетаний р и Т, равновесных по отношению к оксидам $\mathrm{V}_{2} \mathrm{O}_{5}, \mathrm{~V}_{6} \mathrm{O}_{13}, \mathrm{VO}_{2}$, можно видеть на фазовой диаграмме

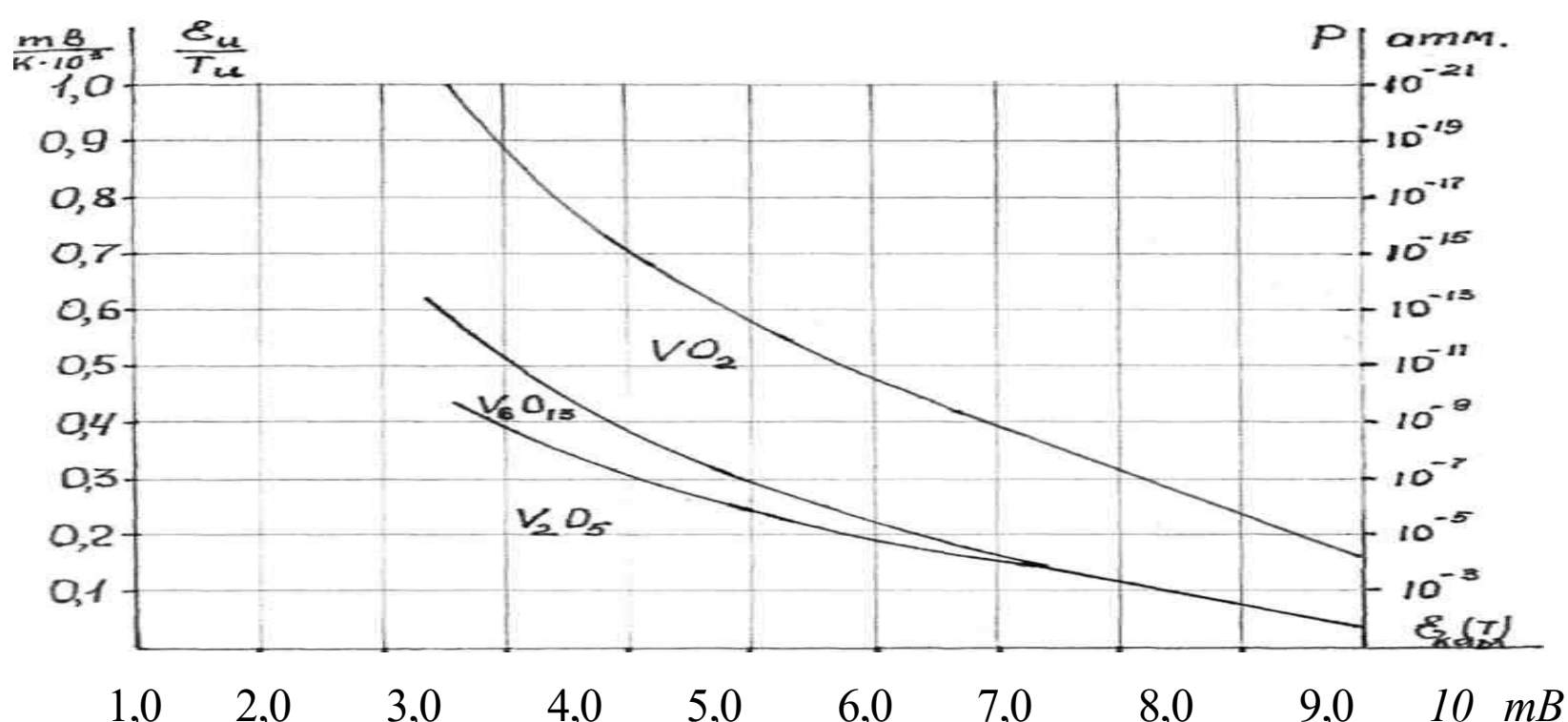

Рис.1. Фазовая диаграмма системы ванадий - кислород

Из нее следует, что сколько бы мы ни выдерживали ванадий при р и Т , отвечающих точкам, лежащим выше верхней границы области $\mathrm{VO}_{2}$, получим фазу, содержащую кислорода меньше, чем $\mathrm{VO}_{2}$. Выдерживая ванадий при р и $\mathrm{T}$ , отвечающих точкам, лежащим ниже нижней границы области $\mathrm{VO}_{2}$, получим $\mathrm{V}_{6} \mathrm{O}_{13}$ либо $\mathrm{V}_{2} \mathrm{O}_{5}$. Однако фазовая диаграмма отражает только термодинамическую сторону процесса. Важную, иногда определяющую роль играет кинетика окисления. При недостаточно высоких температурах 
равновесная степень окисления не достигается, либо достигается за такие большие времена, что окисление целесообразно производить при значениях кислородного потенциала выше равновесного. В последнем случае возникает опасность переокисления образца [183].

Для расширения возможностей исследования и оптимизации технологии окисления необходимы средства непрерывного управления парциальным давлением кислорода в течение процесса. Наилучшим из таких средств является кислородный насос, основанный на использовании транспортных свойств стабилизированной двуокиси циркония, и предназначенный для дозирования кислорода в атмосфере инертного газа .

Принцип действия и основные характеристики такого кислородного насоса заключается в уникальном прикладном свойстве суперионика - проводить через себя исключительно ионы кислорода под воздействием поля постоянного тока и высокой температуры.

Чтобы реализовать исключительные возможности кислородного насоса, необходимо при разработке устройства строго выполнять требования к вакуумной плотности керамики и соединений с магистралью, к технологии электродов и к режимам эксплуатации [184]. Для получения пленок $\mathrm{VO}_{2}$ путем окисления в регулируемой атмосфере разработана установка, включающая в себя кислородный насос на основе стабилизированной двуокиси циркония. Блок - схема кислородного насоса , сконструированного для установки синтеза пленок $\mathrm{VO}_{2}$, показана на рис. 3. 


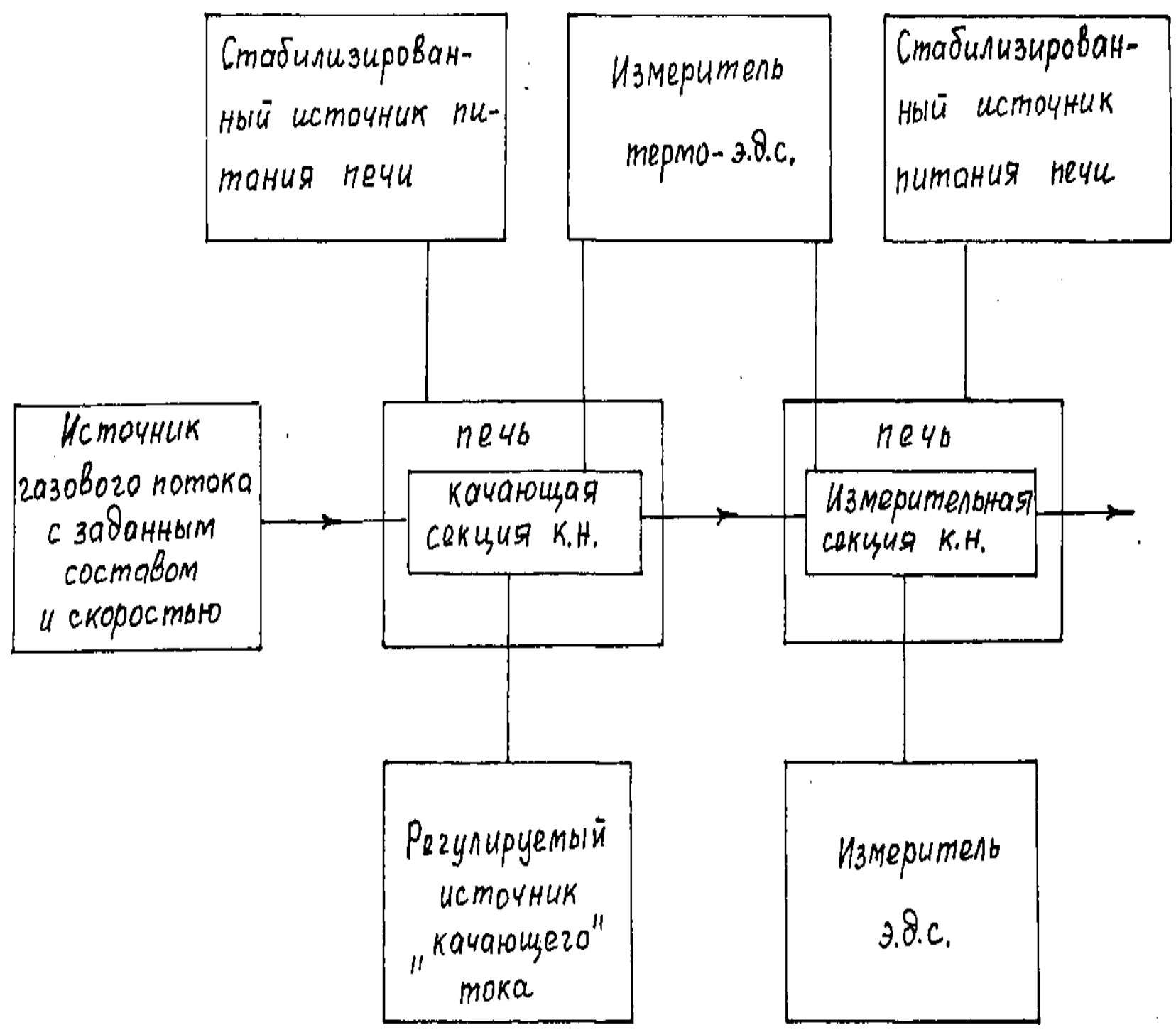

Рис. 3. Блок-схема кислородного насоса

Кроме собственно кислородного насоса в нее входят электрические печи сопротивления со стабилизированными источниками питания, стабилизированный источник качающего тока, схемы измерения температуры и э.д.с. измерительной секции, источник газового потока с заданным составом и скоростью. Источник газового потока включает в себя баллон со сжатым аргоном с известной примесью кислорода $\mathrm{p}_{0}=10^{-5}$ атм., игольчатый вентиль для регулирования потока, систему осушки и измеритель скорости.

Кислородный насос подключается к электрическим цепям, как показано на рис.2. Здесь 1- собственно суперионик, 2,3 - наружные и внутренние электроды, 4 термопара. 


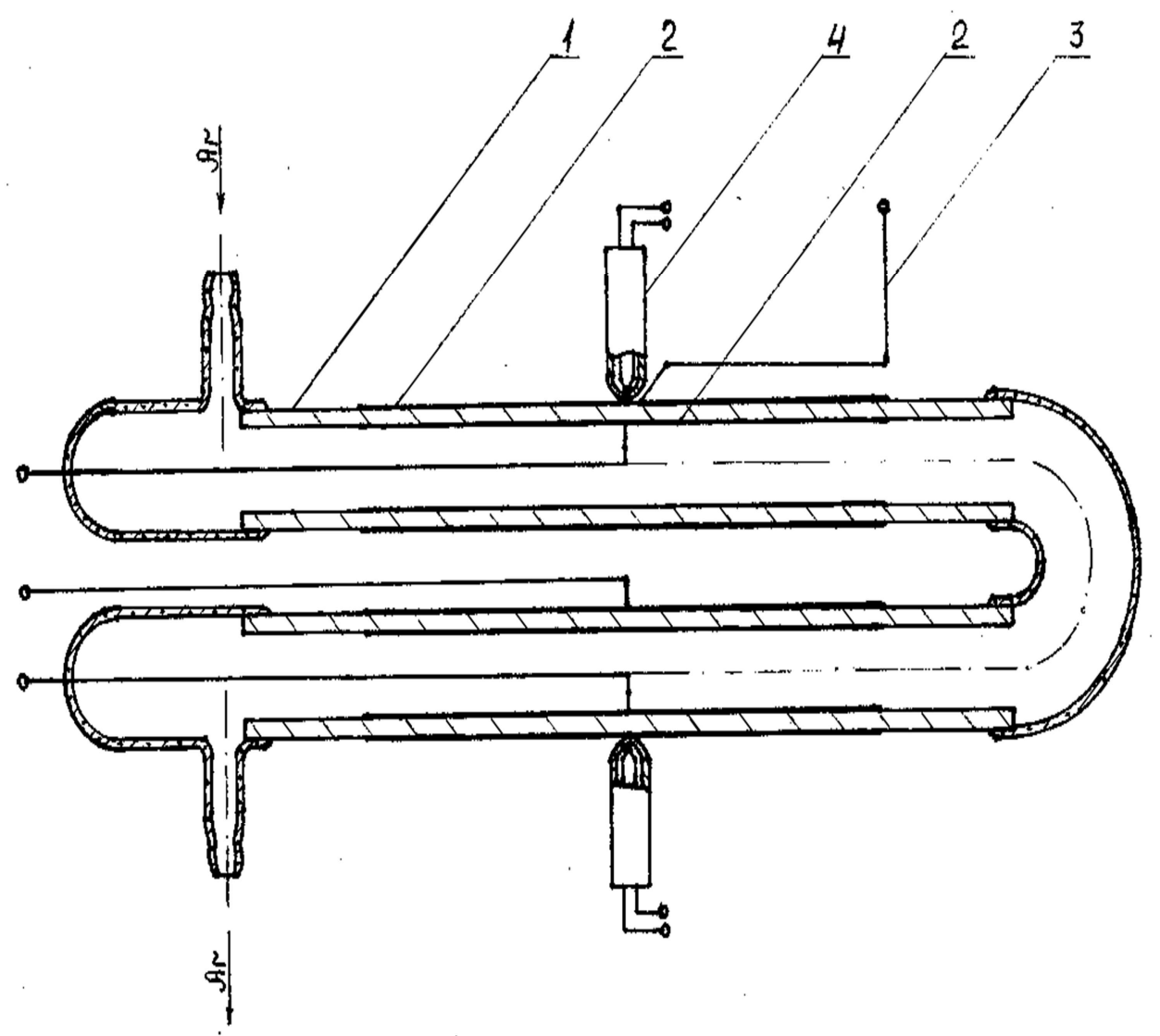

Рис.2. Кислородный насос для дозирования в потоке инертного газа

Качающая и измерительная секции во избежание гальванической связи между ними смонтированы на двух последовательно соединенных трубках I из керамики состава $\mathrm{Z}_{\mathrm{r}} \mathrm{O}_{2}+9$ моль. \% $\mathrm{Y}_{2} \mathrm{O}_{3}$. Длина трубки 240 мм, диаметр 10 мм, толщина стенки I мм. Электроды 2 получены двукратным вжиганием платиновой пасты при $900{ }^{\circ} \mathrm{C}$ в течение одного часа. Длины качащей и измерительной секций составляют соответственно 100 и 5 мм. Токоотводы 3 выполнены из платиновой проволоки диаметром 0,5 мм, црипеченной к пастовому покрытию. Платино - платинородиевые термопары 4 смонтированы непосредственно на качающей и измерительной секциях. Кислородный насос подсоединен к технологической камере, в которой производится окисление пленок ванадия [185].. Камера (рис.4) представляет собой трубу из оптического кварца 1 диаметром 60 мм, длиной 600 мм. Труба укреплена вертикально запаянным концом вверх. 


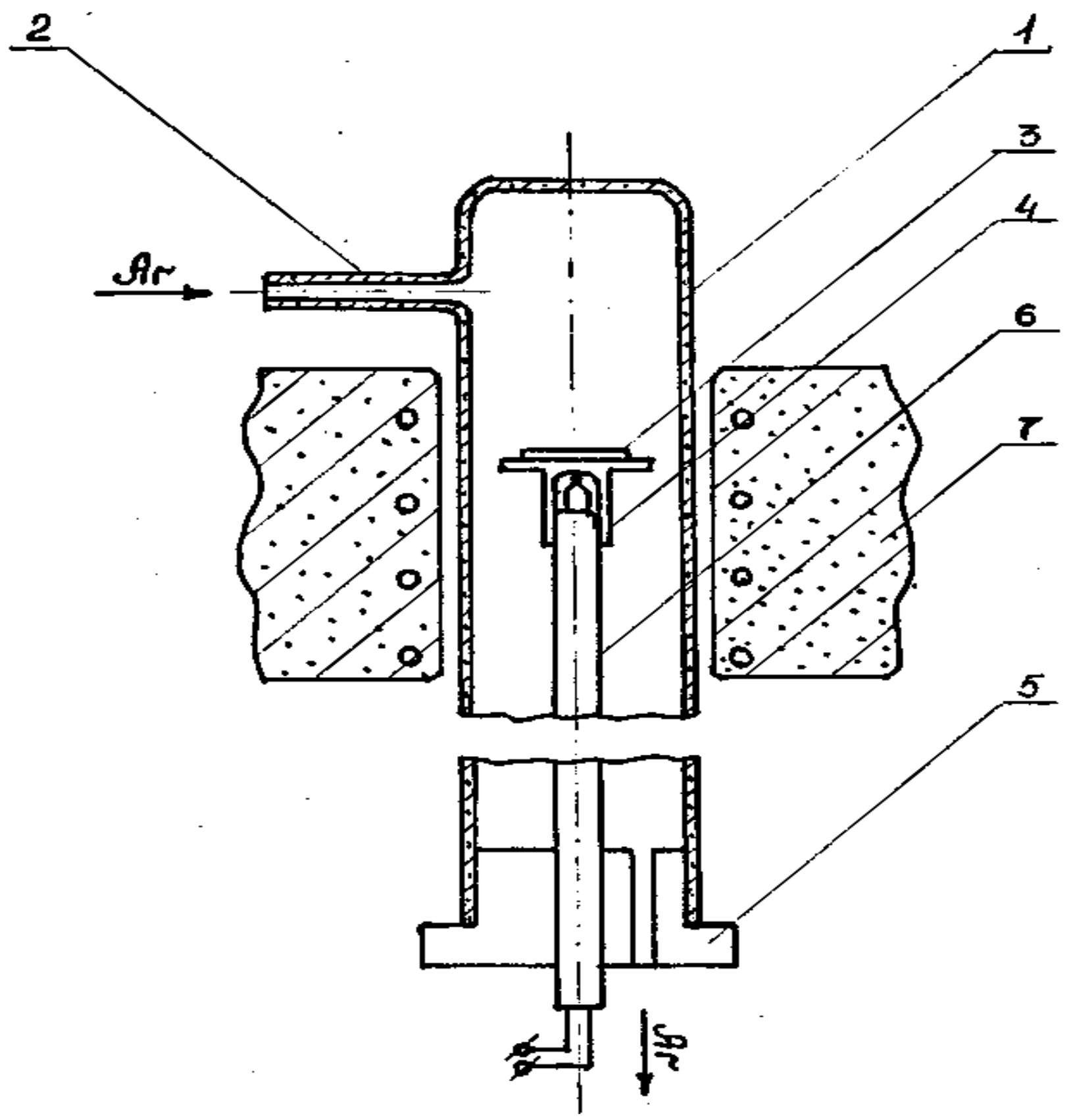

Рис.4. Технологическая камера для окисления пленок ванадия

Газ - аргон с концентрацией кислорода, задаваемой кислородным насосом, поступает в камеру через трубку 2, расположенную в верхней части. Образец 3 в виде пленки ванадия на ситалловой подложке вводится в рабочую зону камеры с помощью держателя 4, укрепленного на съемной пробке 5 с отверстием дяя выхода газа.

В держателе смонтирована термопара 6 для измерения температуры образца. Электрическая печь сопротивления 7 с 
стабилизированным источником питания обеспечивает эаданный температурный режим окисления.

В установке предусмотрена возможность непрерывного оптического контроля процесса окисления. Она снабжена лазером ЛГ- 126. Контроль осуществляется на длине волны $\lambda=0,63$ мкм по интенсивности излучения, отраженного от окисляемого образца. В зависимости от текущего значения толщины пленки $\mathrm{VO}_{2}$ меняются условия интерференции излучения, отраженного от поверхности $\mathrm{VO}_{2}$ и металла, что позволяет судить о глубине прокисления образца. Принципиальные схемы системы оптического контроля приведены на рис.5.

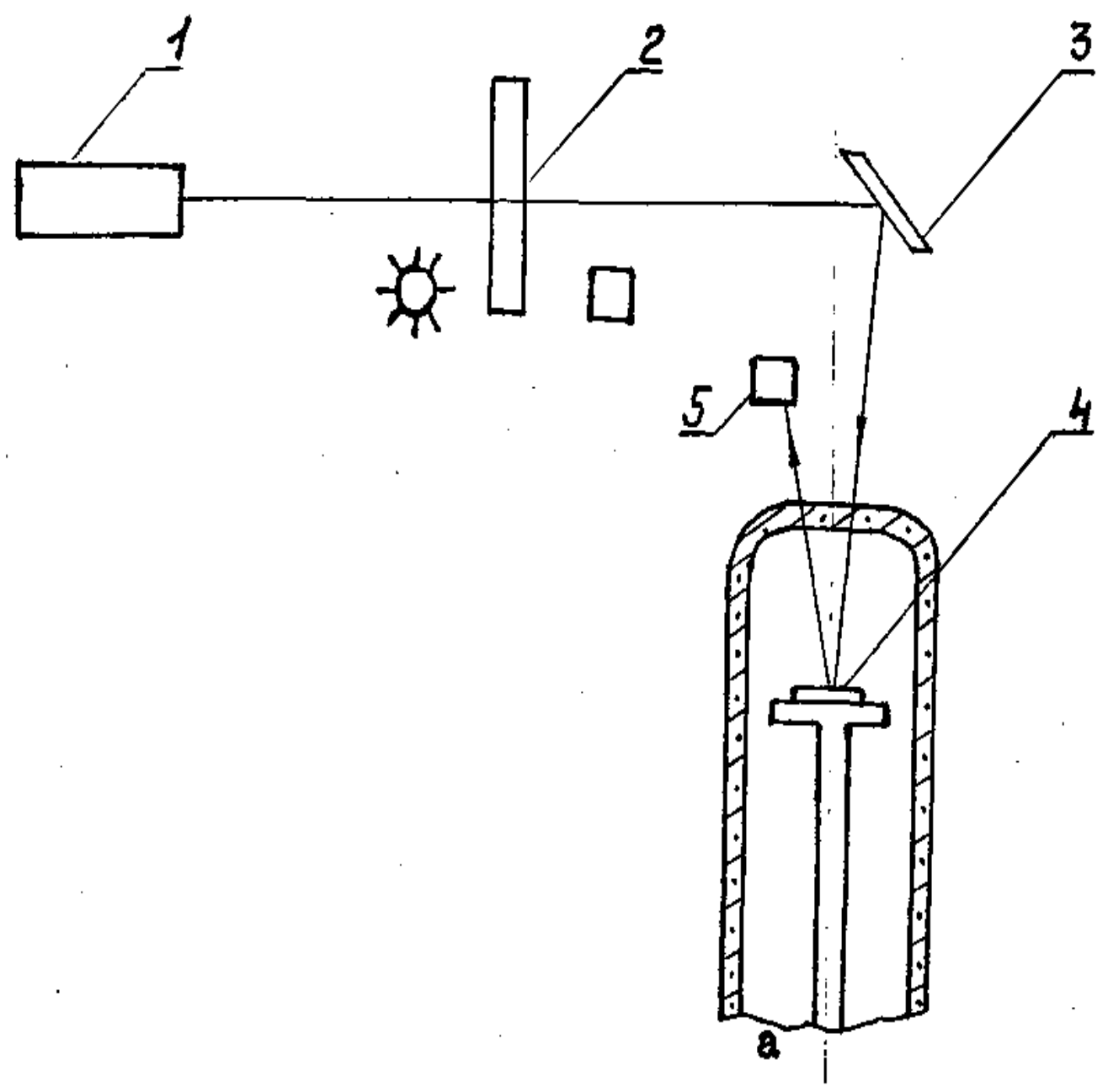

а) оптическая часть схемы 


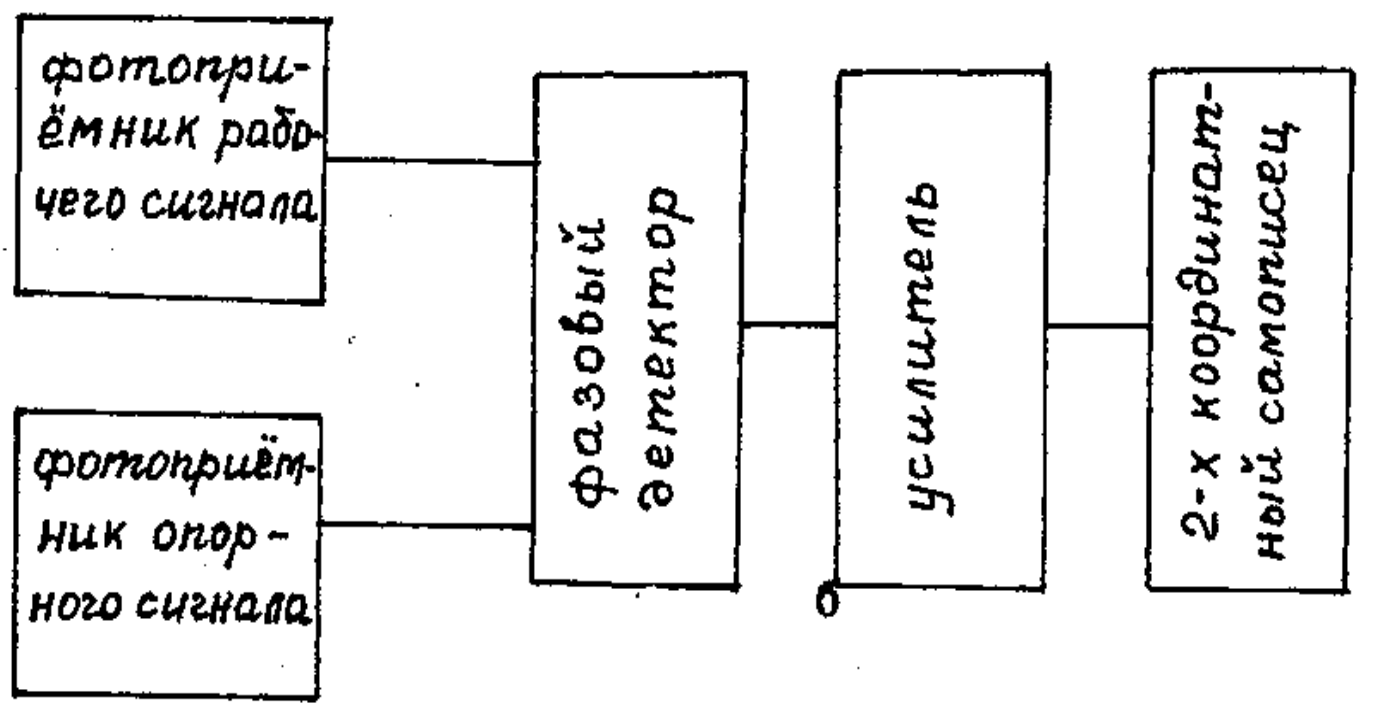

б) электрическая часть схемы

Рис.5. Принципиальные схемы системы оптического контроля окисления пленок ванадия:

Оптическая часть (рис. 5 а) кроме лазера I включает в себя механический прерыватель 2, зеркало 3, образец 4, фотоприемник рабочего сигнала 5. Электрическая часть (рис. 5б) включает фотоприемники рабочего и опорного сигналов, фазовый детектор, усилитель и двухкоординатный самописец [186]..

Подготовка установки начинается с подключения газового баллона и установления требуемой окорости газового потока. Затем следует включить питание печей кислородного насоса и камеры и поднять температуры до заданных значений, причем во избежание теплового разрушения керамики скорость подьема температуры кислородного насоса не должна превышать 300 град/час [187]. Следует заранее включить приборы системы оптического контроля и питание цепи качающей секции, после чего установить ток качающей секции, обеспечивающий требуемое парциальное давление кислорода на выходе р, связанное с э.д.с. измерительной ячейки формулой 


$$
p=p^{\prime} \cdot e^{-\frac{4 F \varepsilon}{\mathrm{RT}}}
$$

Образец пленки ванадия поместить на площадке держателя и ввести его в рабочую зону камеры, после чего настроить систему оптического контроля так, чтобы отраженный от образца луч лазера попал на фотоприемник. В процессе окисления ванадия интенсивность отраженного луча изменяется, при этом наблюдается отчетливая интерференционная картина, по которой можно судить о глубине прокисления образца [188] .

Парциальное давление кислорода и температура в рабочей камере подбираются опытным путем с учетом следущих обстоятельств. С одной стороны химический потенциал кислорода $\mu_{\mathrm{o}_{2}}$ должен быть достаточно близким к равновесному по отношению к фазе $\mathrm{VO}_{2}$ (для того, чтобы не образовывались другие окислы). Однако, с другой стороны, в процессе приближения к равновесию сильно эамедляется скорость релаксации системы (в данном случае скорость окисления). Фактически для того, чтобы получать пленки $\mathrm{VO}_{2}$ за разумное время, значение $\mu_{\mathrm{o}_{2}}$ должно быть выше равновесного, но не настолько, чтобы получались переокисленные формы. Это условие удалось реализовать при $\mathrm{T}=480-520^{\circ} \mathrm{C}$ и $\quad p_{\mathrm{o}_{2}}=10^{-2}-10^{-3}$ атм. [189].

Чтобы упростить воспроизведение каждого заданного режима, ордината на фазовой диаграмме рис. I кроме единиц парциального давления кислорода, отградуирована также в единицах отношения / T , которое как следует из формулы (2), однозначно связано с р на выходе кислородного насоса. Еще удобнее выбирать температуру измерительной секции $\mathrm{T}=727^{\circ} \mathrm{C}$ и пользоваться шкалой $10^{-3} \mathrm{~B} / \mathrm{K}$, т.е. непосредственно показаниями прибора, измеряющего э.д.с. измерительной секции[190]. Абсцисса на фазовой диаграмме кроме ${ }^{\circ} \mathrm{C}$ проградуирована также в единицах э.д.с. платино-платинородиевой термопары, измеряющей температуру образца. Синтезированная таким образом полупроводниковая пленка диоксида ванадия служит главным образом, как фотохромный материал для записи и хранения оптической информаций, как переключатель, основанный на фазовом переходе металл - полупроводник, как фазовый трансформационный интерференционный реверсивный отражатель света. [191]. Методика получения полупроводниковой 
пленки в контролируемой атмосфере с помощью суперионика, требует специальных ограничений к техническим условиям изготовления кислородного насоса. В этом смысле подразумеваются:

- исключительно кислородноионная проводимость суперионика (стабилизированной двуокиси циркония);

- строгая герметичность узловых соединений керамики со стеклом;

- отсутствия натекания молекулярного кислорода из вне 